\title{
Design of Lifting and Rotating Device Used in Water Tank
}

\author{
Xianbo Zeng ${ }^{1, a}$, Zhiyong $\mathrm{Li}^{2, \mathrm{~b}}$,Wenjian Wang ${ }^{3, \mathrm{c}}$ \\ ${ }^{1}$ Qingdao Harbour Vocational and Technology College, Qingdao 266404, P.R.China \\ ${ }^{2}$ Shandong University of Science and Technology, Qingdao 266590, P.R.China \\ ${ }^{3}$ Beijing Great Wall Institute of Measurement and Testing Technology, Beijing 100095, P.R.China \\ azengxbtr@163.com, 'bZY5552270@163.com, 'DWJ@bbn.cn
}

Keywords: Lifting and rotating device; Structure of sound; PLC

\begin{abstract}
The lifting and rotating device is applied to areas increasingly. The high frequency lifting and rotating device described in this paper is mainly used to control the position of the structure of sound to be tested in the water tank, PLC controller is selected to control the $\mathrm{X}$ axis, $\mathrm{Y}$ axis, $\mathrm{Z}$ axis and the rotary angle, and demonstrates each date through touching screen monitor THA62-MT, the device has advantages of simple operation, further improved in the accuracy of the data collection, it is of great significance for practical application.
\end{abstract}

\section{Introduction}

This paper introduces a self-developed lifting and rotating device with high frequency used in tank, It is mainly used to control the position of the structure of sound to be tested in the water tank. Qin Qin designed the control system of an anechoic tank's lifting and rotating positioning device, it improved the precision of lifting and rotating positioning device, and it made the system more convenient and usable[1]. Jing Lin et al design the rotary rise lifting device used on the lake platform, actual results show the system is running stably and reliability[2]. Design cases of two different lifting and rotating positioning device for the same application are introduced by Bin Tang et al, and the characteristics of two types of structure are discussed[3]. Most previous studies are limited to the design of the part of the lifting and rotating device. Based on the above mentioned reference design, the paper introduces the overall design of the device. In addition, Mateti, Kiron et al have a study on the wing rotation and lift modeling and measurement in SUEX flapping wing mechanisms, damping defect is obvious[4]. Barnett R L. et al examine several hidden dangers associated with a particular class of lifts that are "frame engaging"[5].

\section{Overall Mechanical and Electrical Design of Lifting and Rotating Device}

Function Requirements and Technical Indexes. The function requirements of the device is that the device can be used to control the position of the structure of sound to be tested in the water tank and the $\mathrm{X}$ axis, $\mathrm{Y}$ axis, $\mathrm{Z}$ axis and the rotary angle, and the device also can record the information.

The main technical indexes are shown in Table 1, Table 2 and Table 3.

Table 1 Motion range

\begin{tabular}{|c|c|c|c|c|}
\hline X Direction & Y Direction & Z Direction & Rotating angle & Pitching angle \\
\hline$\geq 1600 \mathrm{~mm}$ & $\geq 1000 \mathrm{~mm}$ & $\geq 1000 \mathrm{~mm}$ & $\pm 360^{\circ}$ & $\pm 20^{\circ}$ \\
\hline \\
Table 2 Measurement accuracy and Control accuracy \\
\hline & \multicolumn{2}{|c|}{ Linear displacement } & \multicolumn{2}{c|}{ Rotating angle } \\
\hline Measurement accuracy & $\begin{array}{c}\leq \pm 0.05 \mathrm{~mm} ; \\
\text { resolution is } 0.01 \mathrm{~mm}\end{array}$ & $\begin{array}{c}\leq \pm 0.05^{\circ} ; \\
\text { resolution is } 0.01^{\circ}\end{array}$ \\
\hline Control accuracy & $\leq \pm 0.5 \mathrm{~mm}$ & $\leq \pm 0.1^{\circ}$ \\
\hline
\end{tabular}

Table 3 The velocity of the linear and rotary motion

\begin{tabular}{|c|c|c|}
\hline & Maximum velocity & Minimum velocity \\
\hline Linear motion & $\geq 2 \mathrm{~m} / \mathrm{min}$ & $0.1 \mathrm{~m} / \mathrm{min}$ \\
\hline Rotary motion & $\geq 1080^{\circ} / \mathrm{min}$ & $1.8^{\circ} / \mathrm{min}$ \\
\hline
\end{tabular}


The load bearing of the device is $20 \mathrm{~kg}$.

The range of application temperature is $0-40^{\circ} \mathrm{C}$.

The range of application moisture is less than $90 \% \mathrm{RH}$.

Design of Electromechanical Control System. The control system is mainly constituted by PLC XCC-32T and THA62-MT and self-developed circuits. The basic structure of the control system is shown in Figure 1.

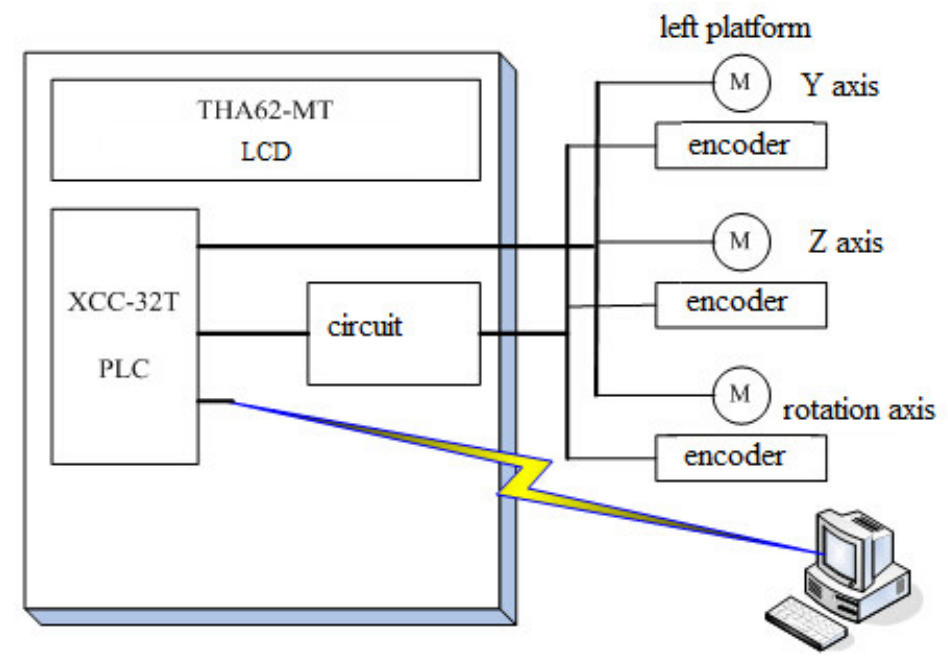

Figure 1 The basic structure of the control system

There are 8 axes which 3 are electronic control on the platform, and the Y-axis, Z-axis, rotation axis on the sliding platform 1 are controlled by PLC. The data of the displacement sensor are read by PLC which combined with self-developed circuits. The RS485 of PLC provide computer remote interface, LCD Monitor show the displacement data and receive the operating instructions.

\section{Structural Design of the Lifting and Rotating Device}

Mechanical System. The mechanical system is mainly constituted by sliding platform 1 and sliding platform 2 which can slide along the $\mathrm{X}$ direction and $\mathrm{Y}$ direction. There is a lifting and rotating device on each platform, and the device can drive the connecting shaft to do the vertical and rotary motion.

The device is suitable for the tank whose size is less than $1600(\mathrm{~L}) \times 1000(\mathrm{~W}) \times 1000(\mathrm{H})$. The coordinate of $\mathrm{Y}$ direction, $\mathrm{Z}$ direction and $\theta$ direction in platform 1 can achieve control and positioning by automatic, the operator can accurately control the direction of movement through the console or computer program, and they also can operate by manual mode after the termination of the electric mode. Platform 2 is controlled on manually operation, operator can operate in hand wheel.

The whole device is a separate one, the moving platform are made of aluminum alloy frame of linear cell structure. Screw and guide rail and other components are enclosed in the frame. The surface of anodized aluminum rust, the overall appearance and generous.

All of the electric motor are driven by a stepping motor through the turbine reducer and drive mechanism, and it provided with a displacement sensor in various degrees of freedom of the last stage. Displacement sensors measure the displacement of movement of each degree of freedom and feedback to the control system, and the platform can achieve the precise positioning automatically.

The mechanical structure of the lifting and rotating device is shown in Figure 2. 


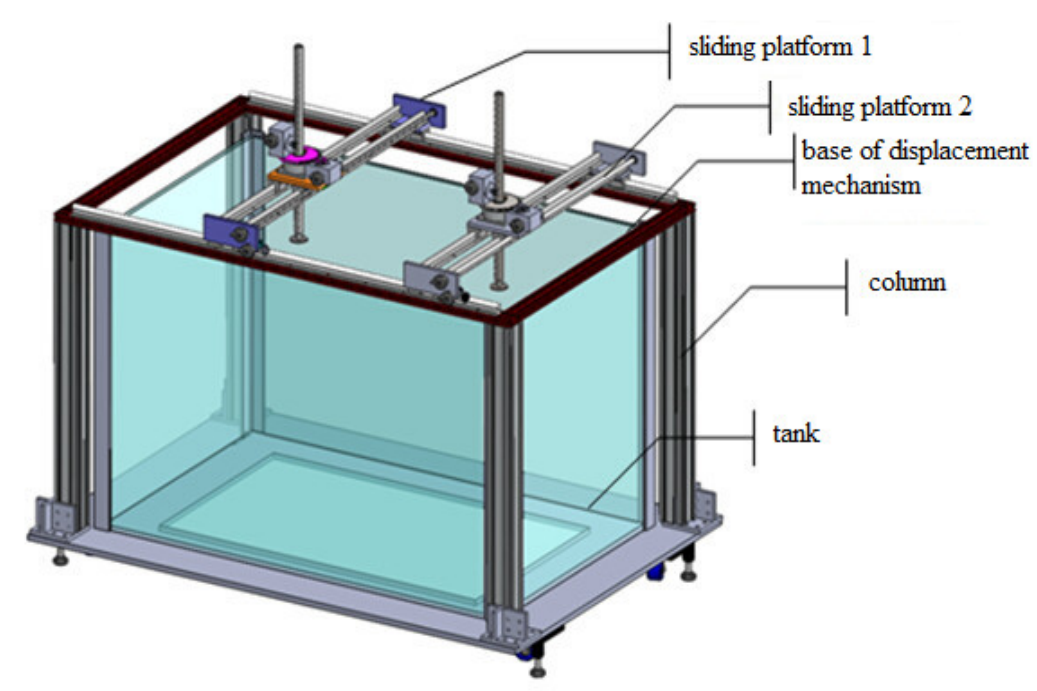

Figure 2 The mechanical structure of the lifting and rotating device

Sliding platform in $\mathrm{X}$ direction is installed on the base frame through $\mathrm{X}$ guide, it is the guide mechanism combined linear guide with bracket and open type linear bearing, and its transmission mode is pinion and rack. The advantages of the design is convenient for manual operation, and the structure is very simple.

Sliding platform in $\mathrm{Y}$ direction is on the $\mathrm{X}$, and it has the same guide mechanism with $\mathrm{X}$, the transmission mode adopts stainless steel trapezoidal screw rectilinear motion. The hand wheel with manual operation is placed in a convenient operating position.

Sliding platform mechanism is shown in Figure 3.

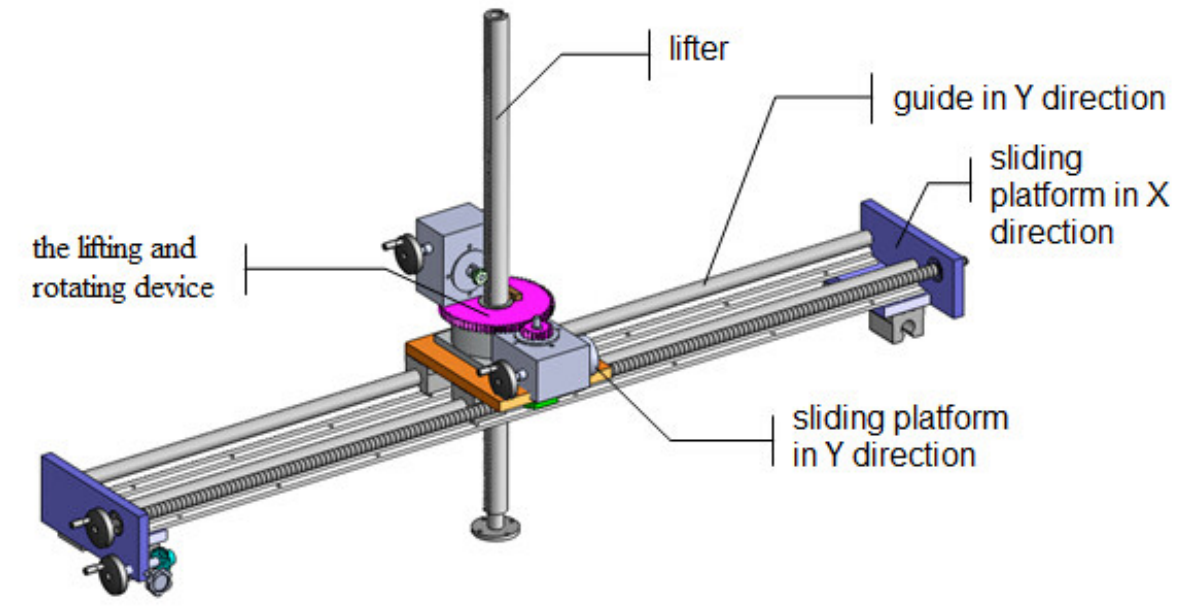

Figure 3 Sliding platform mechanism

The manual function and locking function of the sliding platform is shown in Table 4.

Table 4 The manual function and locking function of the sliding platform

\begin{tabular}{|c|c|c|}
\hline X Direction & Manual function & Locking function \\
\hline Y Direction & $\begin{array}{c}\text { Screw installed on the end of } \\
\text { the hand wheel }\end{array}$ & Trapezoidal screw friction \\
\hline Z Direction & $\begin{array}{c}\text { The input shaft of worm gearing } \\
\text { reducer mounted handle }\end{array}$ & $\begin{array}{c}\text { Self-locking with worm } \\
\text { gearing reducer }\end{array}$ \\
\hline$\theta$ Direction & $\begin{array}{c}\text { The input shaft of worm gearing } \\
\text { reducer mounted handle }\end{array}$ & $\begin{array}{c}\text { Self-locking with worm } \\
\text { gearing reducer }\end{array}$ \\
\hline
\end{tabular}




\section{Working Principle of the Measuring System}

Measurement of Displacement. The encoder is fixed to the end of the screw on the measuring system of linear motion, it can calculate the relative amount of displacement through the number of rotation of screw and the number of pulses. Measuring system of rotation is fixed on the rotary table, the encoder can output the corresponding positive pulse signal based on the amount and direction of rotation when the turret rotate.

PLC counter count on the pulse according to the digital of pulse and direction, then it will obtain the current amount of displacement.

The encoder will ensure the accuracy of the measurement and calibration. The measurement resolution and precision are shown in Table 5.

Table 5 The measurement resolution and precision

\begin{tabular}{|c|c|c|}
\hline & Measurement resolution & Precision \\
\hline$X$ axis & $0.01 \mathrm{~mm}$ & $\pm 0.05 \mathrm{~mm}$ \\
\hline Y axis & $0.01 \mathrm{~mm}$ & $\pm 0.05 \mathrm{~mm}$ \\
\hline$Z$ axis & $0.01 \mathrm{~mm}$ & $\pm 0.05 \mathrm{~mm}$ \\
\hline$\theta$ axis & $0.01^{\circ}$ & $\pm 0.05^{\circ}$ \\
\hline
\end{tabular}

The rotary encoder is a relative displacement sensor, the initial value of the absolute amount of displacement is input by manually. The accuracy of the displacement measurement of the device is determined by the accuracy of the displacement sensor.

Obtain Absolute Coordinates. The measurement system need to obtain absolute coordinates incase of power failure or the first use after installed. The absolute displacement measurement system is input by the operator directly, and it can be modified at any time.

Preservation of Displacement. The process of the absolute coordinates acquired can be conducted at any time in accordance with instructions, but the process need to spend some time. In order to improve the efficiency of work, the motion controller will save the value of displacement in the case of normal shutdown, and the value will be read automatically by the controller at the next boot.

\section{Summary}

This paper introduces the design of a self-developed lifting and rotating device with high frequency used in tank in detail, and the working principle of the measuring system was introduced. The device has advantages of simple operation, further improved in the accuracy of the data collection, and it is of great significance for practical applications.

\section{References}

[1] Qin Qin, Mechanical Engineering \& Automation, 2011(04): p. 151-152.

[2] Jing Lin, Weijie Jiang, and Feng Lin, Transducer and Microsystem Technologies, 2010(12): p. 137-140.

[3] Bin Tang, Wenjian Wang, and Hua Wang, Measurement Technology, 2012(03): p. 30-32.

[4] Mateti K, Byrne-Dugan R A, Tadigadapa S A, et al. Wing Rotation and Lift Modeling and Measurement in SUEX Flapping Wing Mechanisms[A]. ASME 2012 Conference on Smart Materials, Adaptive Structures and Intelligent Systems[C]. American Society of Mechanical Engineers, 2012, 591-599.

[5] Barnett R L, Glauber J B. Automotive Lifts: Unrestrained vs. Restrained Swing Arms[A]. ASME 2009 International Mechanical Engineering Congress and Exposition[C]. American Society of Mechanical Engineers, 2009, 373-387. 